\title{
Towards integrated coastal zone management, with a special emphasis on the Mediterranean Sea: Introduction
}

\author{
Micallef, A.S. \\ Director, Euro-Mediterranean Centre on Insular Coastal Dynamics, \\ Foundation for International Studies, St. Paul Street, Valletta, VLT 07, Malta. \\ Fax+356 21 245764; E-mail a.micallef@icod.org.mt
}

\section{Background}

In this Special Feature, resulting from a MEDCOAST conference held in Hammamet, Tunisia, some papers are presented on ecological and biological research related to integrated coastal zone management. All over Europe coastal environments are threatened by human activities such as urbanization, industrial development, fisheries, aquaculture, recreation and tourism. Research has to be developed that can be applied to similar case studies in different countries. Methods of monitoring are necessary and baseline data have to be available in order to judge the significance of changes in the abiotic and biotic environment. Examples of studies included in this Special Feature are mainly from southern banks of the Mediterranean Sea but there is also an example from Estonia and one from the Canary Islands.

\section{Survey of papers}

The twelve papers presented in this Special Feature of the Journal of Coastal Conservation were originally presented at the Fifth International Conference on the Mediterranean Coastal Environment (MEDCOAST 01) organized in Hammamet, Tunisia in October 2001. While the field of study addressed by the MEDCOAST biannual series of international conferences deals with the coastal environment in its widest sense, this Special Feature is primarily concerned with Coastal Conservation and Management. In addition, the papers were selected to reflect a region-wide geographic distribution, providing studies which may be of relevance to the widest possible audience.

Four papers specifically address management and planning of coastal resources. Abul-Azm et al.present an overview of an ICZM project on Egypt's Fuka-Matrouh coastline, undertaken within the UNEP/MAP Coastal Area Management Programme (CAMP). The paper outlines results of the project, reviews the established methodology and discusses the contribution to sustainable development of the northwest Egyptian coast enabled by this national experience. The authors relate the management framework followed by this project to the national ICZM programme in Egypt (initiated in 1996) as established through environmental legislation enacted in 1994. In conclusion, the authors consider the recommendations issued by this project that proposed, in the short term, to define guidelines for regional planning and preparation of a general Structure Plan for the coastal area, and, as long-term objectives, the preparation and implementation of an ICZM plan for Egypt's Mediterranean coastal area, and definition of related sectoral projects.

The paper by Johnson \& Dagg highlights the importance of public participation in coastal planning and considers the difficulty of implementing this in practice. The authors use a case study concerning a port expansion in the U.K. to discuss benefits and methodologies concerning, in particular, consideration of which sections of the public should be involved and at what stage. The need for skilled personnel and adequate resources is discussed as a prerequisite for successful decision making concerning major development projects in the often complex coastal area. In conclusion, the authors discuss the need for improved guidelines for developers, enhanced standardization of public involvement, training for forum facilitators and increased awareness from environmental pressure groups regarding the complexity of integrating public participation with decision making.

The paper by Andreeva et al. reviews legal policy pertaining to integrated coastal area management in Russia, reflecting on the challenges faced by the new Russian Federation following upheavals in the former Soviet Union in managing the enormous coast under its jurisdiction. Through the presentation of a draft legislative act on ICZM, the authors promote the concept of considering the coast as a natural resource to be managed rather than solely as an environment to be protected, and discuss efforts to harmonize social, economic and environmental issues in the coastal areas with sustainable development of coastal communities, as well as considering existing legislation, international 
commitments and overseas experience in this field.

Veloso-Gomes \& Taveira-Pinto present a number of recently developed 'Seafront Land-Use Management Plans' in Portugal and consider the relevance of such plans to integrated coastal area management in the country. The authors identify a number of key limitations that must be addressed within these plans in order to enable effective management and better encompass the entire coastal environment. Specific issues include poor availability of field data, unsatisfactory consideration of harbour and estuarine areas, an over-representation of municipal authority interests, unaddressed stakeholder conflicts of interest and a poor institutional and management infrastructure.

Of the three papers that address coastal erosion and beach dynamics, van der Salm \& Unal discuss beach nourishment on the Italian coast as a management approach for shoreline protection and rehabilitation, and for the provision of improved recreational amenities. The authors use a number of case studies to define the role of public and private stakeholders in project evolution, and the multiple issues that should be addressed in the evaluation and execution stages of any beach nourishment project. Key decision making based on correct and wide-scoped socio-economic and environmental information, knowledge of the available range of solutions, acceptance of multi-sectorial participation and contribution, competent forecasting of environmental tolerance and reaction, expert management and the use of specialists are among the necessary conditions identified by the authors for successful projects.

Valpreda \& Simeoni present a GIS application describing the national case study evaluating coastal erosion susceptibility in Italy. The authors describe the methodology (conceptual framework and progress of application) used in the creation of this GIS, which takes the form of a risk assessment model describing limitations imposed by data availability (in terms of quality and quantity) for the national coastal zone. The authors suggest that despite its limitations, this national GIS should contribute to enhanced data sharing and dissemination, improved application of GIS systems and adoption of a standardized and nationally referenced cartographic system.

Anfuso et al. consider beach sediment dynamics on the Chipiona-Rota coast of south-west Spain. The results of a morphodynamic monitoring project are presented for a $14 \mathrm{~km}$ length of sandy coast interspersed with rocky shore platforms. The study identified three main beach classes, namely low reflective, dissipative and rocky shore platform beaches. The main phenomenon identified and discussed in this paper is that longitudinal beach sediment distribution is not linked to beach distance from sediment source and/or regional long-shore currents prevalent in the area, but rather to local bathymetric contouring and the resulting impact on wave breaking processes. The authors deduce that as a consequence, a very irregular long-shore variation of morphodynamic beach states has been established in this area.

Four papers address various aspects of coastal management which often are relevant for tourism. Dolgen et $a l$. for example, deal with the need for improved management in Turkish marinas. More specifically, the authors consider the limitations of developing countries in achieving Best Waste Management Programmes and consider, as a case study, waste management practice at the Kusadasi Setur marina in Turkey. In addressing the relevance of boat-generated wastes to improved marina management, Dolgen et al. consider the control of wastewater, bilge wastes, solid wastes and other wastes generated by boat hull cleaning. Finally, the authors evaluate the potential benefits of quality awards, such as the Blue Flag, that may contribute to improved management practice in marinas.

Through a review of recent Italian legislation concerning the protection of inland, transitional, coastal and ground-water bodies, Casazza et al. present new concepts where the environmental quality of a water body is considered in terms of its ecological and chemical status. In addition, this case study is used to compare national coastal water quality requirements with those put forward by the European Community Water Framework directive (2000), highlighting innovative features of the Italian legislation, such as the development of a trophic index for classification of coastal waters. In their conclusions, the authors identify the need for further work on the establishment of biological indicators and indices and on the correct characterization of different coastal water body types, which would reflect different classification criteria for specific eco-regions.

Cassar reviews integrated coastal area management practice in two specially protected areas on the Maltese Islands, Ghajn Tuffieha on the northwest coast of Malta and Ramla bay on Gozo. The author describes the challenging management regimes implemented in these two recreationally important sites that simultaneously represent features of ecological and scientific importance at the national level. The novel management approach described involves a strong emphasis on Government decentralization through the involvement of an nongovernmental organization in the direct management of the two sites, under a joint government/EU funding mechanism. In presenting this scenario as a model for similar initiatives in the Mediterranean, the author reviews achievements made to date as well as the future 
challenges to ongoing management.

On the same theme of insular coastal conservation and management, Arisci et al. consider the development of sustainable tourism practice on the Nebida-Capo Pecora southwestern coast of the Italian island of Sardinia. The authors describe and classify a range of environmental (geotopes and biotopes) and cultural monuments, and discuss the need to appropriately evaluate and manage these resources. They propose an integrated model for sustainable tourism development of this outstanding coastal landscape, based on a series of thematic maps describing the local geology, geomorphology, land cover and use, land evaluation and industrial archaeology.

Finally, making use of wider-scoped space satellite applications, Gade et al. discuss the effectiveness of using different remote sensing data (SAR, ATSR, ERS2 and SeaWiFS) to study marine ecosystems on the Spanish Costa Dorada. More specifically, the authors present the findings of a plume dispersion study of two rivers (Ebro and Llobregat) and an industrial wastewater outlet as a contribution to overall ICZM of the area. An important objective of this study was to confirm the effectiveness of combining different satellite data to overcome single sensor drawbacks such as limited temporal coverage, high dependence on weather and availability of daylight. The authors conclude that the use of different sensors is complementary and results in an improved understanding of observed features. 